\title{
Buckling Analysis of Laminated Composite Panel with Elliptical Cutout Subject to Axial Compression
}

\author{
Hamidreza Allahbakhsh and Ali Dadrasi \\ Mechanical Department, Islamic Azad University, Shahrood Branch, Shahrood, Iran \\ Correspondence should be addressed to Hamidreza Allahbakhsh, allahbakhshy@gmail.com \\ Received 21 April 2012; Revised 25 September 2012; Accepted 11 October 2012 \\ Academic Editor: Jing-song Hong
}

Copyright (C) 2012 H. Allahbakhsh and A. Dadrasi. This is an open access article distributed under the Creative Commons Attribution License, which permits unrestricted use, distribution, and reproduction in any medium, provided the original work is properly cited.

\begin{abstract}
A buckling analysis has been carried out to investigate the response of laminated composite cylindrical panel with an elliptical cutout subject to axial loading. The numerical analysis was performed using the Abaqus finite-element software. The effect of the location and size of the cutout and also the composite ply angle on the buckling load of laminated composite cylindrical panel is investigated. Finally, simple equations, in the form of a buckling load reduction factor, were presented by using the least square regression method. The results give useful information into designing a laminated composite cylindrical panel, which can be used to improve the load capacity of cylindrical panels.
\end{abstract}

\section{Introduction}

Laminated composite shells are widely used in many industrial structures including automotive and aviation due to their lower weights compared to metal structures [1]. Many of these shell structures have cutouts or openings that serve as doors, windows, or access ports, and these cutouts or openings often require some type of reinforcing structure to control local structural deformations and stresses near the cutout. In addition, these structures may experience compression loads during operation, and thus their buckling response characteristics must be understood and accurately predicted in order to determine effective designs and safe operating conditions for these structures.

For predicting the buckling load and buckling mode of a structure in the finite-element program, the linear (or eigenvalue) buckling analysis is an existing technique for estimation [2]. In general, the analysis of composite laminated shell is more complicated than the analysis of homogeneous isotropic ones [3].

In the literature, many published studies investigated the buckling of laminated composite plates with a cutout [4-10]. Few studies are available on buckling of composite panel. Kim and Noor [11] studied the buckling and postbuckling responses of composite panels with central circular cutouts subjected to various combinations of mechanical and thermal loads. They investigated the effect of variations in the hole diameter; the aspect ratio of the panel; the laminate stacking sequence; the fiber orientation on the stability boundary; postbuckling response and sensitivity coefficients.

Mallela and Upadhyay [12] presented some parametric studies on simply supported laminated composite panels subjected to in-plane shear loading. They analyzed many models using ANSYS, and a database was prepared for different plate and stiffener combinations. Studies are carried out by changing the panel orthotropy ratio, pitch length (number of stiffeners), stiffener depth, smeared extensional stiffness ratio of stiffener to that of the plate, and extensional stiffness to shear stiffness ratio of the shell.

Transverse central impact on thin fiber-reinforced composite cylindrical panels with emphasis on the importance of in-plane membrane effects was studied by Kistler and Waas [13]. Both small and large deformation impact responses were examined in their work. A nonlinear system of equations was derived for the impact problem, including Hertz' contact law, and solved over time using Runge-Kutta integration.

An analytical method developed for determining the interlaminar stresses at straight free boundaries was extended 

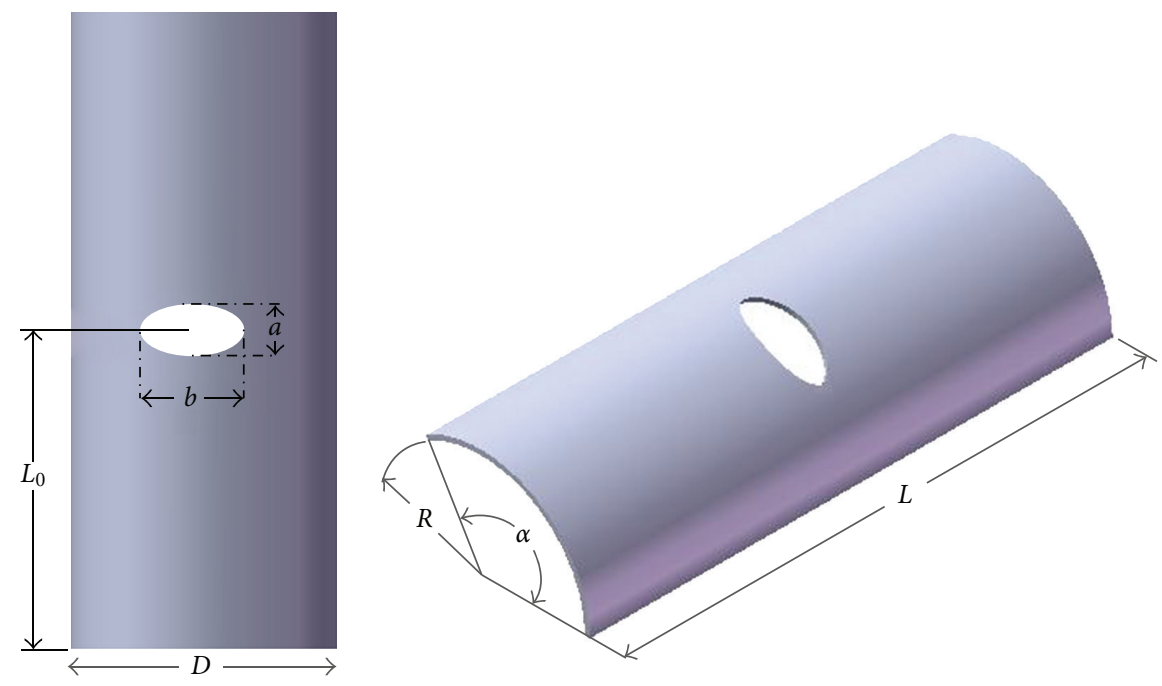

Figure 1: Geometry of panel.

to predict the free-edge stresses at curved boundaries of symmetric composite laminates under in plane loading by Chao Zhang et al. [14]. They described the three-dimensional (3D) stress distribution in laminates with curved boundaries on the basis of a zero-order approximation of the boundarylayer theory. The related stress functions were found by minimization of complementary energy and the variational principle and satisfy zero-order equilibrium equations, boundary conditions, and traction continuity at interfaces between plies.

$\mathrm{Hu}$ and Yang [15] optimized the buckling resistance of fiber-reinforced laminated cylindrical panels with a given material system and subjected to uniaxial compressive force with respect to fiber orientations by using a sequential linear programming method together with a simple movelimit strategy. The significant influences of panel thicknesses, curvatures, aspect ratios, cutouts, and end conditions on the optimal fiber orientations and the associated optimal buckling loads of laminated cylindrical panels have been shown through their investigation.

Dash et al. [16] presented vibration and stability of laminated composite curved panels with rectangular cutouts using finite-element method. The first-order shear deformation (FSDT) is used to model the curved panels, considering the effects of transverse shear deformation and rotary inertia. Dash's studies reveal that the fundamental frequencies of vibration of an angle ply flat panel decrease with introduction of small cutouts but again rise with increase in size of cutout. However, the higher frequencies of vibration continue to decrease up to a moderate size of cutout and then rise with further increase of size of cutout. The stability resistance decreases with increase in size of cutout in curved panels unlike the frequencies of vibration. Gal et al. [17] studied the buckling behavior of laminated composite panel, experimentally and numerically.

This paper studies the buckling behavior of laminated composite panel with elliptical cutout. Also, it presents parametric studies to investigate the effect of the cutout size, cutout location, panel parameters, and ply angle on the buckling of the laminated composite panel. A set of linear analyses using the ABAQUS were carried out and were validated by comparing against solution published in literature. Finally, a set of formulas (based on the numerical results) for the computation of the buckling load reduction factor for laminated composite panel with elliptical cutouts are presented.

\section{Geometry and Mechanical Properties of the Panels}

The structure that is used for analyze is shown in Figure 1. The test specimen is a cylindrical panel with ellipti$\mathrm{cal} /$ circular cutout. According to this figure, parameter (a) displays the size of the cutout in longitudinal axis of the panel, and parameter (b) displays the size of the cutout along the circumferential direction of the panel. Specimens were nominated as follows: $L 300-R 250-a-b-\alpha$. The numbers following $L$ and $R$ show the radius and length of the panel, respectively. The ply thickness of the composite is $0.125 \mathrm{~mm}$ with the laminate stacking of $[\theta /-\theta]_{3}(\theta$ is measured from the cylinder longitudinal direction), which is antisymmetric about the middle surface, corresponding to the total thickness of $t=0.75 \mathrm{~mm}$.

The nominal orthotropic elastic material properties are listed in Table 1 where the 1 direction is along the fibers, the 2 direction is transverse to the fibers in the surface of the lamina, and the 3 direction is normal to the lamina.

\section{Numerical Analysis Using the Finite-Element Method}

To obtain the buckling predictions and eigenvalue analyses with Abaqus, a "buckle" step is run. Eigenvalue analyses are performed for laminated composite cylindrical panel under axial loading that is the common type of loading studied 

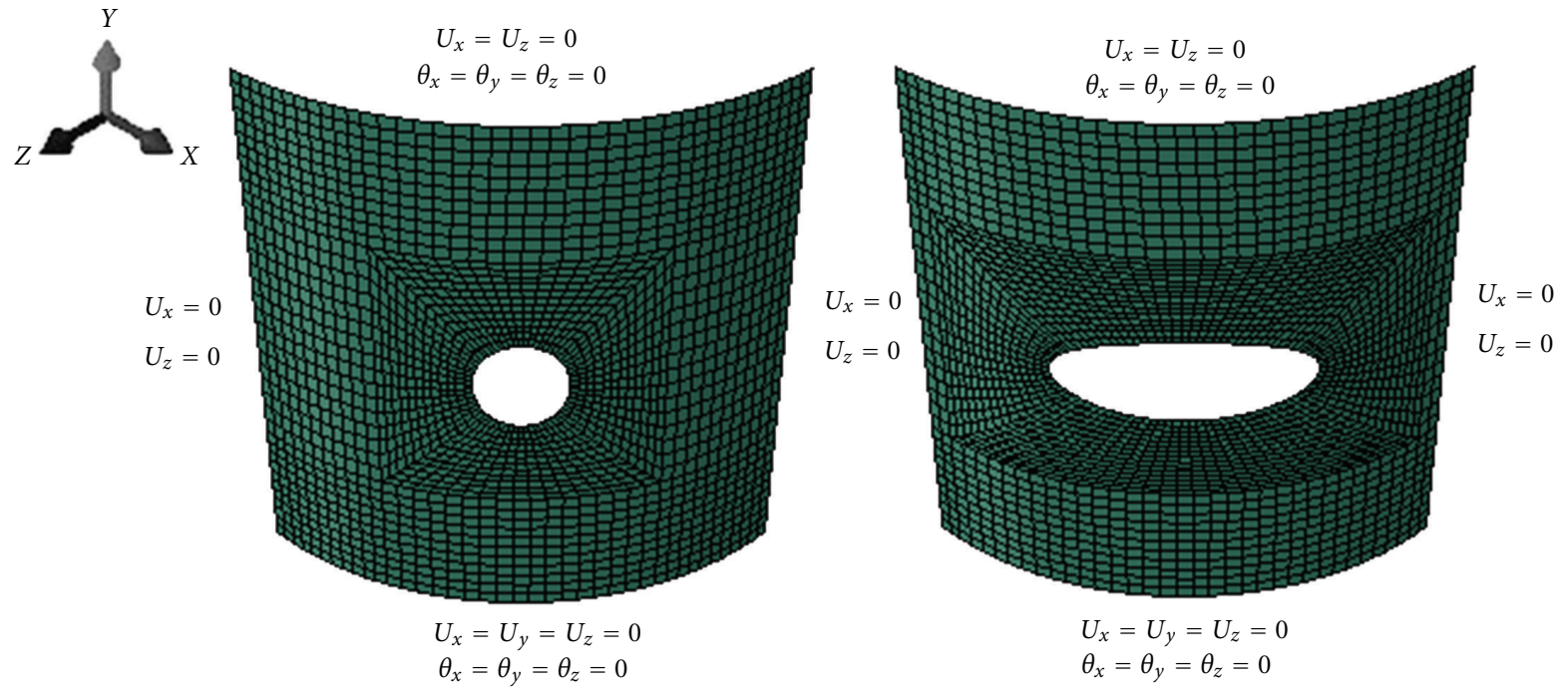

FIGURE 2: Sample mesh structure and boundary conditions.

TABLE 1: Mechanical properties of composite material.

\begin{tabular}{lcccc}
\hline $\begin{array}{l}E_{11} \\
\left(\mathrm{kN} / \mathrm{mm}^{2}\right)\end{array}$ & $\begin{array}{c}E_{22} \\
\left(\mathrm{kN} / \mathrm{mm}^{2}\right)\end{array}$ & $\begin{array}{c}G_{12}, G_{13} \\
\left(\mathrm{kN} / \mathrm{mm}^{2}\right)\end{array}$ & $\begin{array}{c}G_{23} \\
\left(\mathrm{kN} / \mathrm{mm}^{2}\right)\end{array}$ & $\nu_{12}$ \\
\hline 135 & 13 & 6.4 & 4.3 & 0.38 \\
\hline
\end{tabular}

TABLE 2: Mesh convergence study of the cylindrical shells.

\begin{tabular}{lrrrr}
\hline Approximate element size $(\mathrm{mm} \times \mathrm{mm})$ & 3 & 1.5 & 0.75 & 0.4 \\
\hline Buckling load $(\mathrm{kN})$ & 135 & 120 & 109 & 107 \\
$\begin{array}{l}\text { Difference percent with respect to previous } \\
\text { value }\end{array}$ & 11 & 11 & 9.1 & 1.8 \\
\hline
\end{tabular}

for theoretical buckling studies on plates and shells, using FEM.

The panel is fully clamped on the bottom edge, clamped except for axial motion on the top edge, and simply supported along its vertical edges. The eight-node nonlinear element S8R5 which is an element with five degrees of freedom per node was used in analyses. The mesh is divided into two regions for each panel. In the region near the cutout, smaller elements are created, and also a convergence study was conducted for a composite cylindrical panel.

The results obtained from each refinement stage of the mesh were compared with previous stage and were summarized in Table 2.

In order to shun time consuming analyses, an element size equal to $3.5 \mathrm{~mm} \times 3.5 \mathrm{~mm}$ was considered as general element size in the remaining numerical analyses. For this element size, the average aspect ratio of all elements is 1.34 which is adequate. The analyses showed that a typical element size of $0.45 \mathrm{~mm}$ could be used to model the area around the cutout. A typical finite-element model of a composite cylindrical panel with a cutout is shown in Figure 2.

\section{Validation of FE Model for Axial Loading}

To ascertain whether the FE model was sufficiently accurate, it was validated using results from existing experimental, numerical, and theoretical results. In this paper, for validation of FEA, deformation mode and buckling mode are investigated. Figures 3 and 4 show the comparison of results for the present simulations with Stanley [18] results.

\section{Results of Numerical Analysis}

In this section, the results of the buckling analyses of laminated cylindrical panel with elliptical/circular cutouts are presented that was done by finite-element method.

5.1. The Effect of Ply Angle on the Buckling Load. Designing an optimized composite laminate requires finding the best fiber orientation for each layer [20,21]. Figure 5(a) shows the effect of ply angle on buckling shapes of the composite cylindrical panel in first buckling mode. Figure 5(b) displays the dependence of the first buckling load of the laminated composite cylindrical panel on the composite ply angle. For the ply angle in the range of $0<\theta<10$, the first buckling load is associated with buckling shape $\mathrm{A}$, while increasing the ply angle causes buckling shapes $\mathrm{B}, \mathrm{C}, \mathrm{D}$, and $\mathrm{E}$ to precede. For the ply angle in the range of $80<\theta<90$, the buckling shape A has been observed, again. The ply angle of $[70 /-70]_{3}$ occurs to have the maximum load, having about 105\% higher than that of the cylindrical panel with $[0 / 0]_{3}$ stacking. We also investigated the effect of ply angle on the first five buckling loads of the laminated composite cylindrical panels (data not shown for the sake of shortness). These results show that the sensitivity of buckling loads toward the ply angle increases a little for upper buckling modes.

5.2. The Effect of Change in Cutout Height on the Buckling Load. In this section, the effect of change in cutout height 


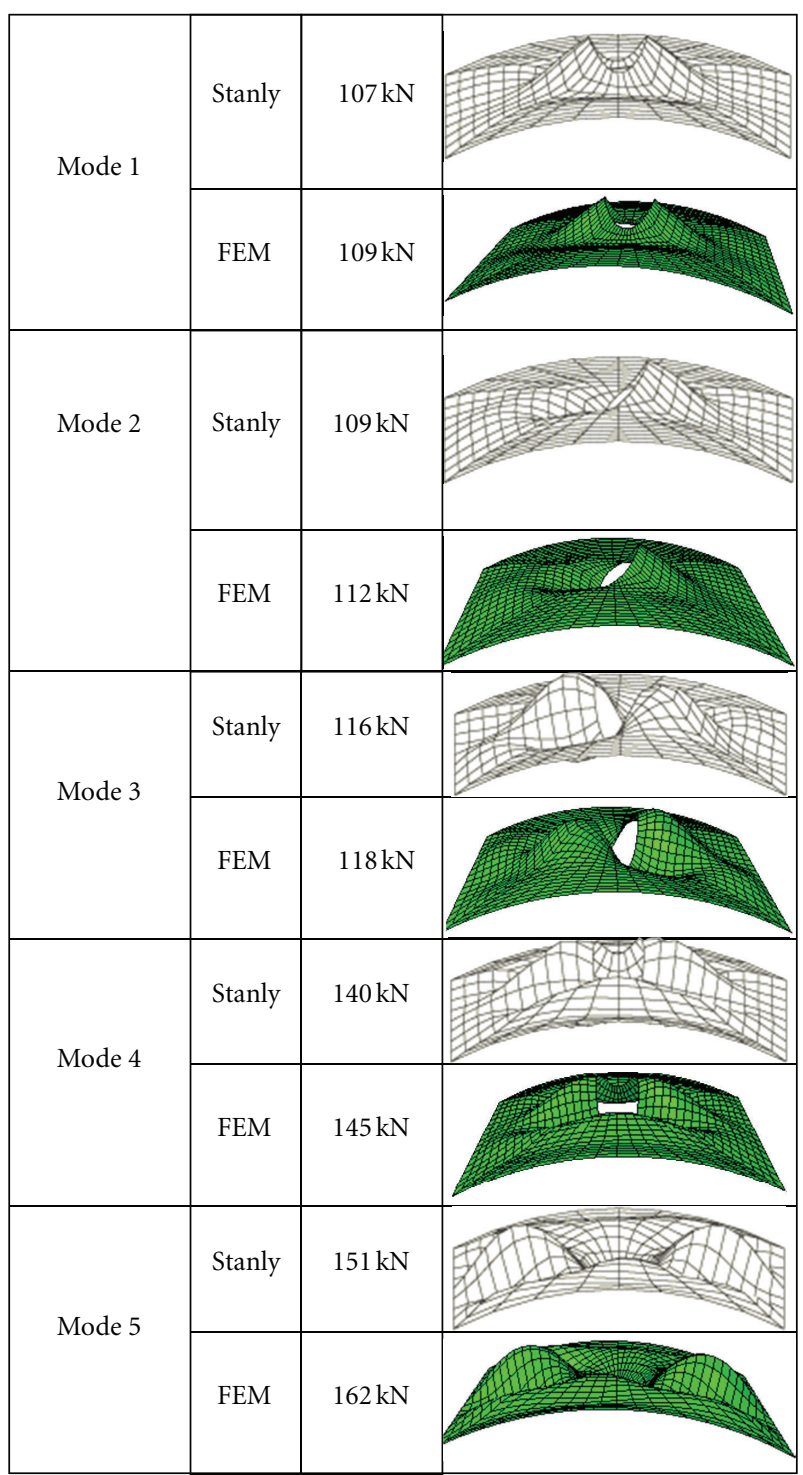

Figure 3: Comparison of the numerical buckling load and mode shape with those obtained by Stanley [18].

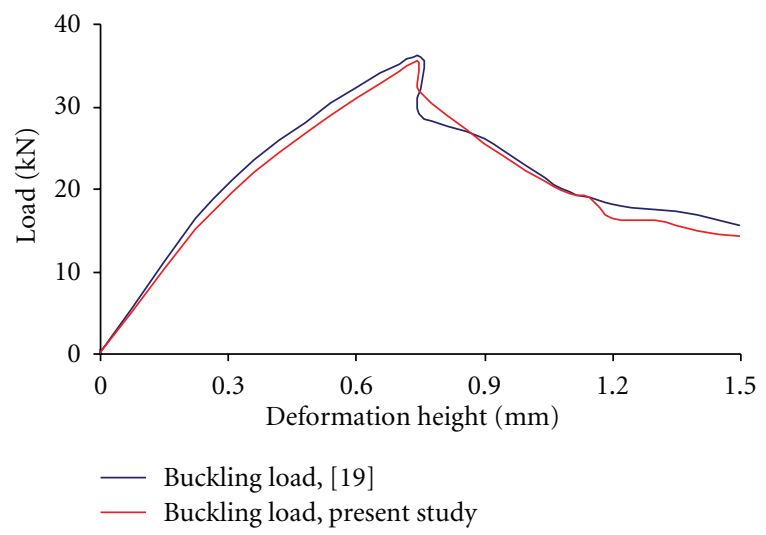

Figure 4: Comparison of the numerical buckling curve with that obtained by Sabik and Kreja [19]. on the buckling load of laminated panel is investigated. To this investigation, cutouts with constant width $(75 \mathrm{~mm})$ were created in the midheight position of panels. Then, we study the change in buckling load with changing the height of the cutouts from 15 to $75 \mathrm{~mm}$. The numerical results are listed in Table 4. Furthermore, Figures 6(a) and 6(b) show buckling load versus $L / D$ and $a / b$ ratios curves, respectively. According to Figure 6(a), it can be seen that buckling load of the laminated panel decreases slightly when the cutout height increases.

For panels with ratios $L / D=0.7, L / D=0.5$, and $L / D=$ 0.3 , with a radius of $400 \mathrm{~mm}$, and with the increase of cutout height from 30 to $75 \mathrm{~mm}$, the buckling load decreases 42,34 , and $31 \%$, respectively. This reduction for panels with ratio $L / D=0.75, L / D=1.25$, and $L / D=1.75$ and with a radius of $500 \mathrm{~mm}$ are 24,20 , and $14 \%$, respectively. Therefore, it can be deduced that longer and slender panels are more sensitive to the change in cutout height. Also Figure 6(b) shows that shells with larger diameters and identical cutouts are more resistant to buckling.

5.3. The Effect of Change in Cutout Width on the Buckling Load. This section investigates the effect of changing the width of the cutout on the buckling load of the laminated composite cylindrical panel. So cutouts with constant height $(30 \mathrm{~mm})$ were created in the midheight of panels. Then, the effect of change in the width of the cutout on the buckling load was studied by changing cutouts width from 30 to $90 \mathrm{~mm}$. The designation and analysis details of each model are summarized in Table 5.

Figures 7(a) and 7(b) show the buckling load versus $a / b$ and $L / D$ ratios curves, respectively. It can be seen that when the cutout height is fix, an increase in the width of the cutout decreases the buckling load.

In laminated cylindrical panels with a radius of $400 \mathrm{~mm}$, the reduction in the buckling load with the increase of width of the cutout from 30 to $75 \mathrm{~mm}$ is 49,42 , and $40 \%$, for panels with ratios $L / D=0.7, L / D=0.5$, and $L / D=0.3$, respectively. In laminated composite panels with a radius of $1000 \mathrm{~mm}$, with the increase of cutout width from 30 to $75 \mathrm{~mm}$, the buckling load decreases 31,27 , and $20 \%$, for panels with ratios $L / D=0.75, L / D=1.25$, and $L / D=1.75$, respectively. So it is evident that longer and slender shells are more sensitive to changes in cutout width.

Comparing the results of this section with those presented in the previous section, it can be deduced that when the cutout height is fixed and cutout width increases $45 \mathrm{~mm}$, the amount of decrease in the buckling load is greater than the corresponding value in the state that the cutout width is fixed and cutout height increases $45 \mathrm{~mm}$. Accordingly, it is suggested that in the design of these panels, whenever possible, the bigger cutout dimension is oriented along the longitudinal axis of the panels.

5.4. Analysis of the Effect of Change in Dimensions of Fixed-Area Cutouts on the Buckling Behavior. The buckling behavior of laminated composite panels with different cutout geometries was studied in the previous sections. In 


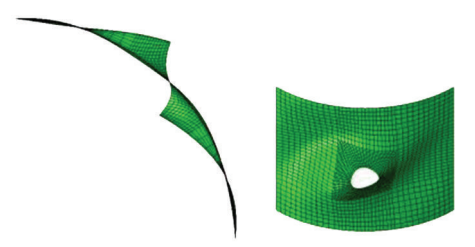

Buckling shape A

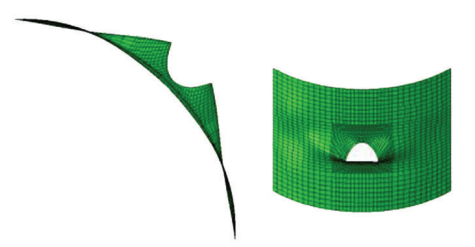

Buckling shape B

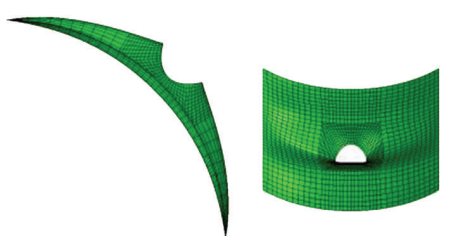

Buckling shape C

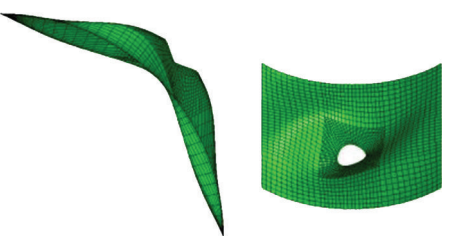

Buckling shape D

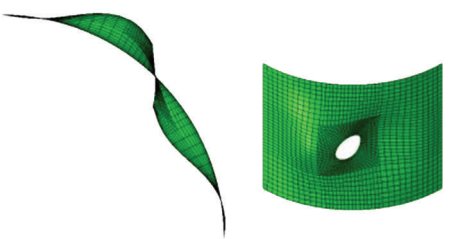

Buckling shape E

(a)

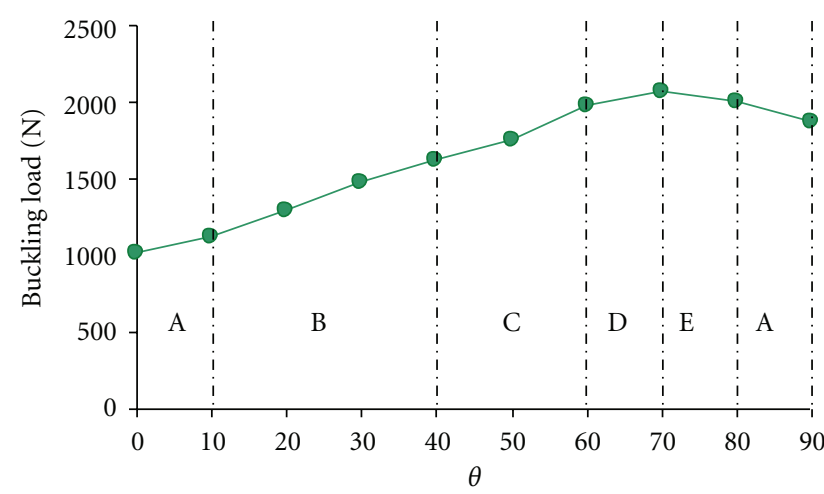

(b)

FIGURE 5: (a) Buckling shapes of a composite cylindrical panel with ply sequence of $[\theta /-\theta]_{3}$, which appear as the first buckling mode depending on the composite ply angle. (b) Variations of the first buckling load of composite cylindrical shell versus the composite ply angle.

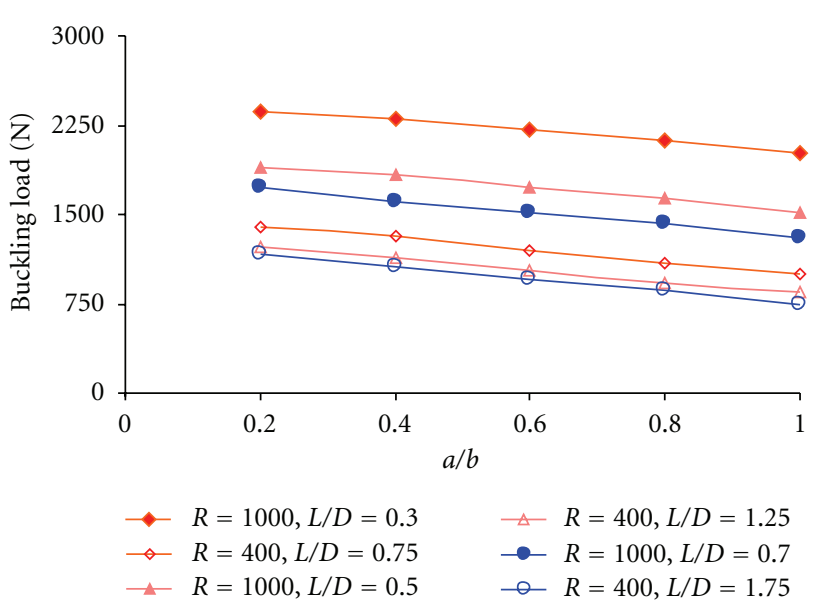

(a)

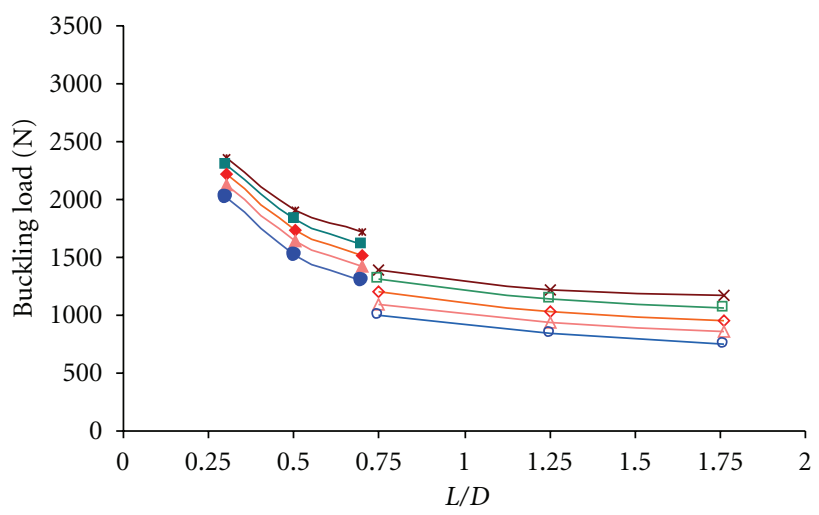

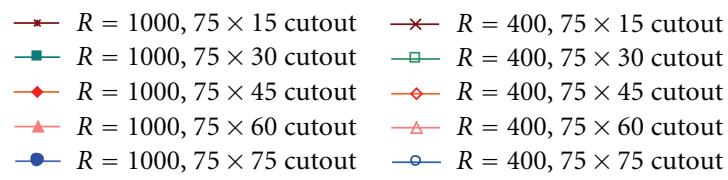

(b)

FIgURE 6: Comparison of the buckling load of laminated composite panel shells versus (a) ratios $a / b$ and (b) $L / D$, for elliptical cutout with constant cutout width and various cutout heights. 


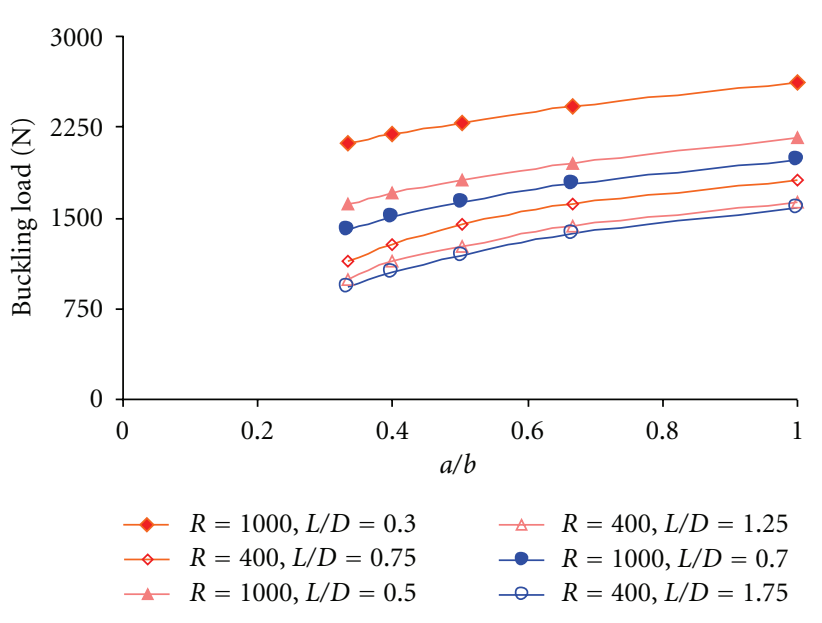

(a)

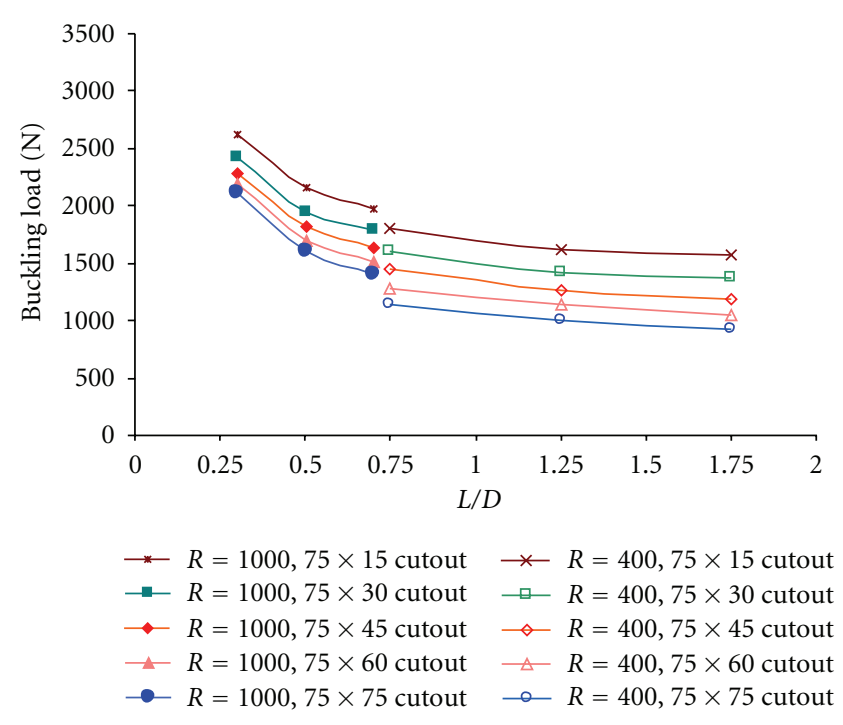

(b)

FIGURE 7: Comparison of the buckling load of laminated composite panel shells versus (a) ratios $a / b$ and (b) $L / D$, for elliptical cutout with constant cutout heights and various cutout widths.

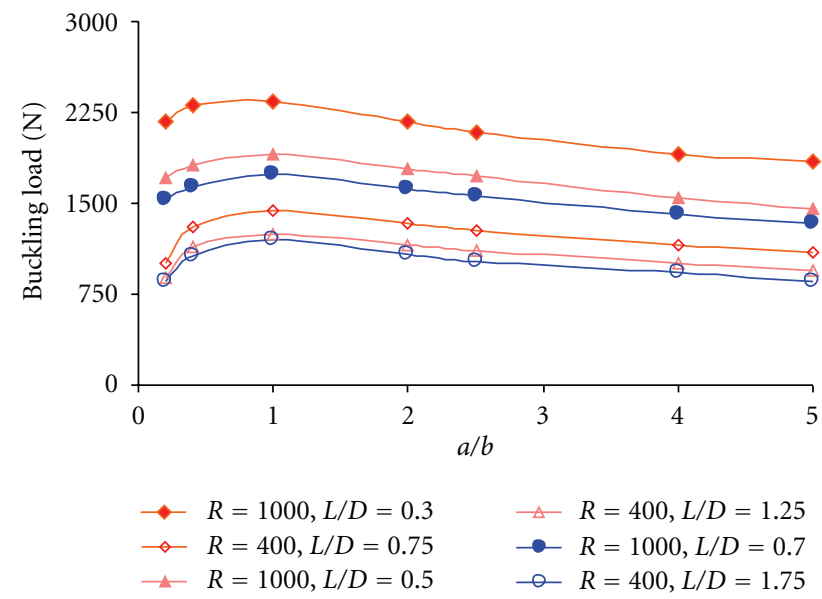

Figure 8: Plots of buckling load versus ratio $a / b$ for cylindrical panel with an elliptical cutout with constant area.

this section, both height and width are changed, so that the product of cutout width and cutout height, which is representative of the area of the cutout, remains constant.

Therefore, cutouts with an area of $A=8242.5 \mathrm{~mm}^{2}$ were created in the midheight of the panels. Seven different values for $\mathrm{a} / \mathrm{b}$ ratio were considered. Figure 8 shows the buckling load versus the $a / b$ ratio curves. Figure 8 clearly shows that for the $a / b$ ratio in the range of $0<a / b<1$, when the cutout area is constant, an increases in $a / b$ ratio increases the buckling load and for $a / b>1$ with increase in $a / b$ ratio decreases the buckling load. On the other hand, having $a / b=1$ results in the highest load capacity.

5.5. Analysis of the Effect of Change in Panel Angle on the Buckling Behavior of Cylindrical Shells. In this section, we

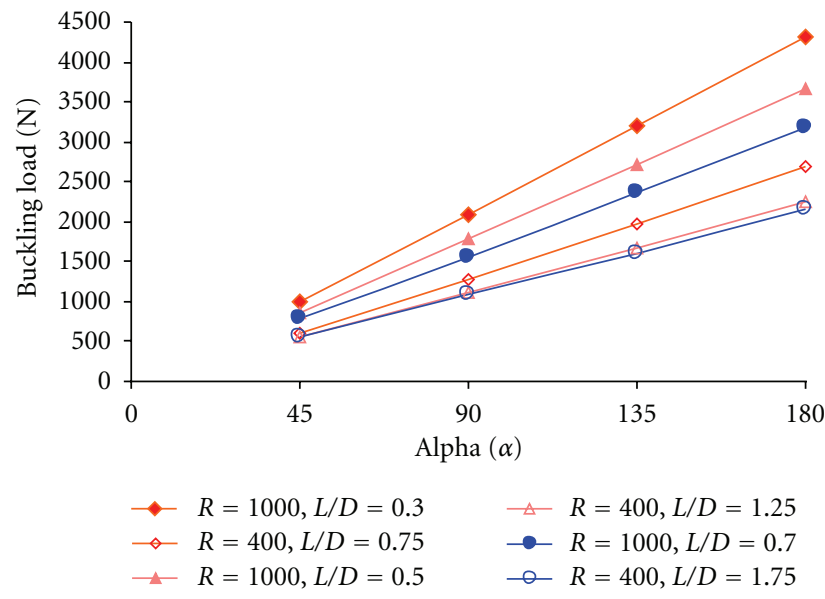

FIGURE 9: Plots of buckling load versus $\alpha$ for cylindrical panel with an elliptical cutout.

investigated the relationship between the buckling load and angle of the laminated panel. For this study, we created an elliptical cutout of constant size $(75 \times 30 \mathrm{~mm})$ in the midheight of the panels with various angles between $45^{\circ}$ and $180^{\circ}$. Figure 9 shows the buckling load versus $L / D$ ratio. It is clear that with an increase in the panel angle, the buckling load of the panels increases. The results show that increasing the panel angle improves the shell resistance against buckling and increases the amount of the critical load. Furthermore, for short, intermediate-length, and long panels with radius of $200 \mathrm{~mm}$, the buckling load increases 313, 300, and 284\%, respectively. Also the buckling load for panel with radius of $500 \mathrm{~mm}$ increases 328,322 , and $300 \%$ for short, intermediate-length, and long panels, respectively. Therefore, slender and longer 
TABLE 3: The formulas for predicting the buckling load reduction factors of laminated cylindrical panel.

\begin{tabular}{lccc}
$\begin{array}{l}\text { Equation } \\
\text { no. }\end{array}$ & Range & Parameters & Equations \\
\hline (3) & $0.75 \leq L / D \leq 1.75$ & $\left(\frac{L}{D}\right),\left(\frac{a}{D}\right)$ & $K_{\text {cutout }}=0.521+0.132\left(\frac{L}{D}\right)-1.004\left(\frac{a}{D}\right)-0.043\left(\frac{L^{2}}{D}\right)-0.080 \frac{L}{D} \frac{a}{D}-0.017 \frac{a^{2}}{D}$ \\
$(4)$ & $0.30 \leq L / D \leq 0.50$ & $\left(\frac{L}{D}\right),\left(\frac{a}{D}\right)$ & $K_{\text {cutout }}=0.311+1.662\left(\frac{L}{D}\right)-0.164\left(\frac{a}{D}\right)-1.327\left(\frac{L^{2}}{D}\right)-1.20 \frac{L}{D} \frac{a}{D}-13.015 \frac{a^{2}}{D}$ \\
$(5)$ & $0.75 \leq L / D \leq 1.75$ & $\left(\frac{L}{D}\right),\left(\frac{b}{D}\right)$ & $K_{\text {cutout }}=0.646+0.250\left(\frac{L}{D}\right)-2.069\left(\frac{b}{D}\right)-0.066\left(\frac{L^{2}}{D}\right)-0.421 \frac{L}{D} \frac{b}{D}+3.166 \frac{b^{2}}{D}$ \\
$(6)$ & $0.30 \leq L / D \leq 0.50$ & $\left(\frac{L}{D}\right),\left(\frac{b}{D}\right)$ & $K_{\text {cutout }}=0.376+1.637\left(\frac{L}{D}\right)-0.777\left(\frac{b}{D}\right)-1.140\left(\frac{L^{2}}{D}\right)-3.033 \frac{L}{D} \frac{b}{D}+0.529 \frac{b^{2}}{D}$ \\
$(7)$ & $0.75 \leq L / D \leq 1.75$ & $\left(\frac{L}{D}\right),\left(\frac{L_{0}}{L}\right)$ & $K_{\text {cutout }}=0.712+0.204\left(\frac{L}{D}\right)-0.999\left(\frac{L_{0}}{L}\right)-0.087\left(\frac{L^{2}}{D}\right)+0.062 \frac{L}{D} \frac{L_{0}}{L}+0.816 \frac{L_{0}}{L}$ \\
$(8)$ & $0.30 \leq L / D \leq 0.50$ & $\left(\frac{L}{D}\right),\left(\frac{L_{0}}{L}\right)$ & $K_{\text {cutout }}=0.350+1.684\left(\frac{L}{D}\right)-0.399\left(\frac{L_{0}}{L}\right)-1.595\left(\frac{L^{2}}{D}\right)+0.553 \frac{L}{D} \frac{L_{0}}{L}+0.232 \frac{L_{0}}{L}$ \\
$(9)$ & $0.75 \leq L / D \leq 1.75$ & $\left(\frac{L}{D}\right),\left(\frac{a}{b}\right)$ & $K_{\text {cutout }}=0.352+0.177\left(\frac{L}{D}\right)+0.072\left(\frac{a}{b}\right)-0.060\left(\frac{L^{2}}{D}\right)-0.005 \frac{L}{D} \frac{a}{b}-0.015 \frac{a^{2}}{b}$ \\
$(10)$ & $0.30 \leq L / D \leq 0.50$ & $\left(\frac{L}{D}\right),\left(\frac{a}{b}\right)$ & $K_{\text {cutout }}=0.292+1.524\left(\frac{L}{D}\right)+0.014\left(\frac{a}{b}\right)-1.202\left(\frac{L^{2}}{D}\right)-0.001 \frac{L}{D} \frac{a}{b}-0.008 \frac{a^{2}}{b}$ \\
\hline
\end{tabular}

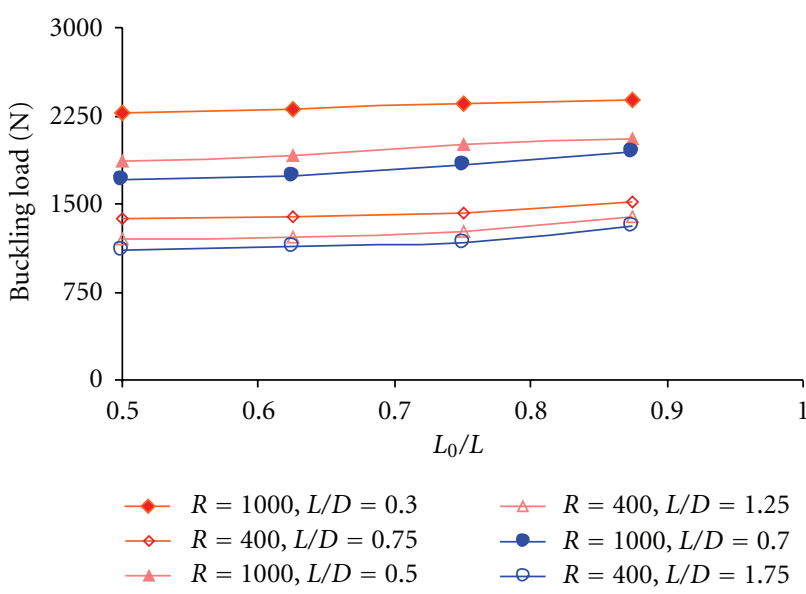

FIGURE 10: Summary of the buckling load of cylindrical panels with elliptical cutout located at various locations.

cylindrical panels are less sensitive to the changes of the panel angle.

5.6. Analysis of the Effect of Change in Cutout Position on the Buckling Load. The buckling load versus the cutout position $\left(L_{0} / L\right)$ ratio curves for cylindrical laminated panel of various lengths are shown in Figure 10. This figure clearly shows that with changing the cutout position from midheight of the panels toward the edges, the buckling load slightly increases. It is clear that longer and slender panels are more sensitive to the change in the position of the cutout. For example, for panels with $L / D=0.7$ and $R=1000$, when the cutout is replaced from the miheight of the panels to $87.5 \%$ of its length, the buckling load increases $13.5 \%$; while for panels with $L / D=0.5$ and $R=1000$, the increase in the buckling load is only $9.7 \%$, and for panels with $L / D=0.3$ and
$R=1000$, the increase in the buckling load is restricted to only $4.3 \%$. Similarly, for panels with $R=400$, with the replace of the position of the cutout from midheight to $87.5 \%$ of panel height, the buckling load changes $17.7 \%, 16.1 \%$, and $10.6 \%$ for ratios $L / D=1.75,1.25$, and 0.75 , respectively.

\section{Prediction of Buckling Load}

The buckling behavior of the laminated composite cylindrical panel subjected to axial compressive loading was presented in the previous sections. Based on the numerical dimensionless buckling loads of panels, formulas are presented for the computation of the buckling load of laminated composite panels with elliptical cutouts subject to axial compression.

$K_{\text {cutout }}$ is introduced as a buckling load reduction factor for cylindrical panels with cutout and defined according to

$$
K_{\text {cutout }}=\frac{N_{\text {cutout }}}{N_{\text {Perfect }}}
$$

where $N_{\text {cutout }}$ and $N_{\text {Perfect }}$ are the buckling load for cylindrical panels with cutouts and the buckling load for cylindrical panels without cutouts, respectively.

The formulas are presented using the least-square regression method [22, 23]. Eight equations ((3)-(10)) were developed for various shell geometries, following the form:

$$
\begin{aligned}
K_{d}(\alpha, \beta, \gamma, \eta, \lambda)= & A+B \alpha+C \beta+D \gamma+E \eta+F \lambda \\
& +G \alpha^{2}+H \beta^{2}+I \gamma^{2}+J \eta^{2}+K \lambda^{2} \\
& +L \alpha \beta+M \alpha \gamma+N \alpha \lambda+O \alpha \lambda+P \beta \gamma \\
& +Q \beta \eta+R \beta \gamma+S \gamma \eta+T \gamma \lambda+U \eta \lambda .
\end{aligned}
$$


TABLE 4: Summary of numerical analysis for cylindrical shells including an elliptical cutout with constant width and different height.

\begin{tabular}{|c|c|c|c|}
\hline Model designation & Shell length & Cutout size $(a \times b)$ & Buckling load $(N)$ \\
\hline R400- $\theta 90-\mathrm{L} 300-\mathrm{L}_{0} 150-\alpha 70$-Perfect & 300 & - & 2535 \\
\hline R400- $\theta 90-\mathrm{L} 300-\mathrm{L}_{0} 150-\alpha 70-15 \times 75$ & 300 & $15 \times 75$ & 1397 \\
\hline $\mathrm{R} 400-\theta 90-\mathrm{L} 300-\mathrm{L}_{0} 150-\alpha 70-30 \times 75$ & 300 & $30 \times 75$ & 1314 \\
\hline $\mathrm{R} 400-\theta 90-\mathrm{L} 300-\mathrm{L}_{0} 150-\alpha 70-45 \times 75$ & 300 & $45 \times 75$ & 1201 \\
\hline R400- $\theta 90-\mathrm{L} 300-\mathrm{L}_{0} 150-\alpha 70-75 \times 60$ & 300 & $60 \times 75$ & 1094 \\
\hline R400- $\theta 90-\mathrm{L} 300-\mathrm{L}_{0} 150-\alpha 70-60 \times 75$ & 300 & $75 \times 75$ & 1000 \\
\hline R400- $\theta 90-L 500-\mathrm{L}_{0} 150-\alpha 70-$ Perfect & 500 & - & 2103 \\
\hline $\mathrm{R} 400-\theta 90-\mathrm{L} 500-\mathrm{L}_{0} 150-\alpha 70-15 \times 75$ & 500 & $15 \times 75$ & 1224 \\
\hline R400- $\theta 90-\mathrm{L} 500-\mathrm{L}_{0} 150-\alpha 70-30 \times 75$ & 500 & $30 \times 75$ & 1139 \\
\hline R400- $\theta 90-L 500-\mathrm{L}_{0} 150-\alpha 70-45 \times 75$ & 500 & $45 \times 75$ & 1030 \\
\hline $\mathrm{R} 400-\theta 90-\mathrm{L} 500-\mathrm{L}_{0} 150-\alpha 70-60 \times 75$ & 500 & $60 \times 75$ & 930 \\
\hline R400- $\theta 90-L 500-\mathrm{L}_{0} 150-\alpha 70-75 \times 75$ & 500 & $75 \times 75$ & 847 \\
\hline R400- $\theta 90-\mathrm{L} 700-\mathrm{L}_{0} 150-\alpha 70$-Perfect & 700 & - & 2004 \\
\hline R400- $\theta 90-\mathrm{L} 700-\mathrm{L}_{0} 150-\alpha 70-15 \times 75$ & 700 & $15 \times 75$ & 1170 \\
\hline $\mathrm{R} 400-\theta 90-\mathrm{L} 700-\mathrm{L}_{0} 150-\alpha 70-30 \times 75$ & 700 & $30 \times 75$ & 1064 \\
\hline R400- $\theta 90-L 700-\mathrm{L}_{0} 150-\alpha 70-45 \times 75$ & 700 & $45 \times 75$ & 960 \\
\hline $\mathrm{R} 400-\theta 90-\mathrm{L} 700-\mathrm{L}_{0} 150-\alpha 70-60 \times 75$ & 700 & $60 \times 75$ & 860 \\
\hline $\mathrm{R} 400-\theta 90-\mathrm{L} 700-\mathrm{L}_{0} 150-\alpha 70-75 \times 75$ & 700 & $75 \times 75$ & 750 \\
\hline R1000- $\theta 90-\mathrm{L} 300-\mathrm{L}_{0} 150-\alpha 70$-Perfect & 300 & - & 3489 \\
\hline $\mathrm{R} 1000-\theta 90-\mathrm{L} 300-\mathrm{L}_{0} 150-\alpha 70-15 \times 75$ & 300 & $15 \times 75$ & 2366 \\
\hline $\mathrm{R} 1000-\theta 90-\mathrm{L} 300-\mathrm{L}_{0} 150-\alpha 70-30 \times 75$ & 300 & $30 \times 75$ & 2300 \\
\hline R1000- $\theta 90-\mathrm{L} 300-\mathrm{L}_{0} 150-\alpha 70-45 \times 75$ & 300 & $45 \times 75$ & 2216 \\
\hline $\mathrm{R} 1000-\theta 90-\mathrm{L} 300-\mathrm{L}_{0} 150-\alpha 70-60 \times 75$ & 300 & $60 \times 75$ & 2125 \\
\hline R1000- $\theta 90-\mathrm{L} 300-\mathrm{L}_{0} 150-\alpha 70-75 \times 75$ & 300 & $75 \times 75$ & 2014 \\
\hline R1000- $\theta 90-L 500-\mathrm{L}_{0} 150-\alpha 70$-Perfect & 500 & - & 2371 \\
\hline R1000- $\theta 90-\mathrm{L} 500-\mathrm{L}_{0} 150-\alpha 70-15 \times 75$ & 500 & $15 \times 75$ & 1900 \\
\hline R1000- $\theta 90-\mathrm{L} 500-\mathrm{L}_{0} 150-\alpha 70-30 \times 75$ & 500 & $30 \times 75$ & 1829 \\
\hline R1000- $\theta 90-\mathrm{L} 500-\mathrm{L}_{0} 150-\alpha 70-45 \times 75$ & 500 & $45 \times 75$ & 1730 \\
\hline $\mathrm{R} 1000-\theta 90-\mathrm{L} 500-\mathrm{L}_{0} 150-\alpha 70-60 \times 75$ & 500 & $60 \times 75$ & 1640 \\
\hline R1000- $\theta 90-\mathrm{L} 500-\mathrm{L}_{0} 150-\alpha 70-75 \times 75$ & 500 & $75 \times 75$ & 1520 \\
\hline R1000- $\theta 90-\mathrm{L} 700-\mathrm{L}_{0} 150-\alpha 70$-Perfect & 700 & - & 2104 \\
\hline R1000- $\theta 90-\mathrm{L} 700-\mathrm{L}_{0} 150-\alpha 70-15 \times 75$ & 700 & $15 \times 75$ & 1720 \\
\hline R1000- $\theta 90-\mathrm{L} 700-\mathrm{L}_{0} 150-\alpha 70-30 \times 75$ & 700 & $30 \times 75$ & 1610 \\
\hline $\mathrm{R} 1000-\theta 90-\mathrm{L} 700-\mathrm{L}_{0} 150-\alpha 70-45 \times 75$ & 700 & $45 \times 75$ & 1520 \\
\hline $\mathrm{R} 1000-\theta 90-\mathrm{L} 700-\mathrm{L}_{0} 150-\alpha 70-60 \times 75$ & 700 & $60 \times 75$ & 1420 \\
\hline $\mathrm{R} 1000-\theta 90-\mathrm{L} 700-\mathrm{L}_{0} 150-\alpha 70-75 \times 75$ & 700 & $75 \times 75$ & 1300 \\
\hline
\end{tabular}

In (2), $\alpha=a / D, \beta=b / D, \gamma=L / D, \eta=a / b$ and $\lambda=L_{0} / L$, in which $a, b, D, L$, and $L_{0}$ signify the cutout height, cutout width, shell diameter, shell length, and cutout location, respectively. The exact form of the resulting equations is summarized in Table 3.

Equation (3) represents the buckling load reduction factor for the cylindrical panel with various lengths $(0.75 \leq$ $L / D \leq 1.75$ ), with an elliptical cutout of fixed cutout width $(b / D=0.1875)$ and various cutout heights $(0.0375 \leq a / D \leq$ $0.1875)$ in the midheight position of the shell.

Equation (4) is the buckling load reduction factor for the cylindrical panel with various lengths $(0.3 \leq L / D \leq 0.5)$, with an elliptical cutout of fixed cutout width $(b / D=0.075)$ and various cutout heights $(0.015 \leq a / D \leq 0.075)$ in the midheight position of the shell.
Equation (5) represents the buckling load reduction factor for the cylindrical panel with various lengths $(0.75 \leq$ $L / D \leq 1.75)$, with an elliptical cutout of fixed cutout height $(a / D=0.1875)$ and various cutout widths $(0.0375 \leq b / D \leq$ 0.1875 ) in the midheight position of the shell.

Equation (6) represents the buckling load reduction factor for the cylindrical panel with various lengths $(0.3 \leq$ $L / D \leq 0.5$ ), with an elliptical cutout of fixed cutout height $(a / D=0.075)$ and various cutout widths $(0.015 \leq b / D \leq$ 0.075 ) in the midheight position of the shell.

Equations (7) and (8) represent the buckling load reduction factor for the cylindrical panel with various lengths $(0.75 \leq L / D \leq 1.75)$ and $(0.3 \leq L / D \leq 0.5)$, with an elliptical cutout of fixed size $15 \times 75 \mathrm{~mm}$ in different positions $(0.875 \leq L / D \leq 0.5)$, respectively. 
TABLE 5: Summary of numerical analysis for cylindrical shells including an elliptical cutout with constant height and different height.

\begin{tabular}{|c|c|c|c|}
\hline Model designation & Shell length & Cutout size $(a \times b)$ & Buckling load $(N)$ \\
\hline R400- $\theta 90-\mathrm{L} 300-\mathrm{L}_{0} 150-\alpha 70$-Perfect & 300 & - & 2535 \\
\hline $\mathrm{R} 400-\theta 90-\mathrm{L} 300-\mathrm{L}_{0} 150-\alpha 70-30 \times 30$ & 300 & $30 \times 30$ & 1806 \\
\hline $\mathrm{R} 400-\theta 90-\mathrm{L} 300-\mathrm{L}_{0} 150-\alpha 70-30 \times 45$ & 300 & $30 \times 45$ & 1611 \\
\hline $\mathrm{R} 400-\theta 90-\mathrm{L} 300-\mathrm{L}_{0} 150-\alpha 70-30 \times 60$ & 300 & $30 \times 60$ & 1446 \\
\hline $\mathrm{R} 400-\theta 90-\mathrm{L} 300-\mathrm{L}_{0} 150-\alpha 70-30 \times 75$ & 300 & $30 \times 75$ & 1286 \\
\hline $\mathrm{R} 400-\theta 90-\mathrm{L} 300-\mathrm{L}_{0} 150-\alpha 70-30 \times 90$ & 300 & $30 \times 90$ & 1140 \\
\hline R400- $\theta 90-\mathrm{L}_{500}-\mathrm{L}_{0} 150-\alpha 70$-Perfect & 500 & - & 2103 \\
\hline $\mathrm{R} 400-\theta 90-\mathrm{L} 500-\mathrm{L}_{0} 150-\alpha 70-30 \times 30$ & 500 & $30 \times 30$ & 1622 \\
\hline $\mathrm{R} 400-\theta 90-\mathrm{L} 500-\mathrm{L}_{0} 150-\alpha 70-30 \times 45$ & 500 & $30 \times 45$ & 1425 \\
\hline $\mathrm{R} 400-\theta 90-\mathrm{L} 500-\mathrm{L}_{0} 150-\alpha 70-30 \times 60$ & 500 & $30 \times 60$ & 1262 \\
\hline $\mathrm{R} 400-\theta 90-\mathrm{L} 500-\mathrm{L}_{0} 150-\alpha 70-30 \times 75$ & 500 & $30 \times 75$ & 1141 \\
\hline $\mathrm{R} 400-\theta 90-\mathrm{L} 500-\mathrm{L}_{0} 150-\alpha 70-30 \times 90$ & 500 & $30 \times 90$ & 995 \\
\hline R400- $\theta 90-\mathrm{L} 700-\mathrm{L}_{0} 150-\alpha 70$-Perfect & 700 & - & 2004 \\
\hline $\mathrm{R} 400-\theta 90-\mathrm{L} 700-\mathrm{L}_{0} 150-\alpha 70-30 \times 30$ & 700 & $30 \times 30$ & 1579 \\
\hline $\mathrm{R} 400-\theta 90-\mathrm{L} 700-\mathrm{L}_{0} 150-\alpha 70-30 \times 45$ & 700 & $30 \times 45$ & 1367 \\
\hline $\mathrm{R} 400-\theta 90-\mathrm{L} 700-\mathrm{L}_{0} 150-\alpha 70-30 \times 60$ & 700 & $30 \times 60$ & 1182 \\
\hline $\mathrm{R} 400-\theta 90-\mathrm{L} 700-\mathrm{L}_{0} 150-\alpha 70-30 \times 75$ & 700 & $30 \times 75$ & 1056 \\
\hline $\mathrm{R} 400-\theta 90-\mathrm{L} 700-\mathrm{L}_{0} 150-\alpha 70-30 \times 90$ & 700 & $30 \times 90$ & 926 \\
\hline R1000- $\theta 90-\mathrm{L} 300-\mathrm{L}_{0} 150-\alpha 70$-Perfect & 300 & - & 3489 \\
\hline $\mathrm{R} 1000-\theta 90-\mathrm{L} 300-\mathrm{L}_{0} 150-\alpha 70-30 \times 30$ & 300 & $30 \times 30$ & 2625 \\
\hline $\mathrm{R} 1000-\theta 90-\mathrm{L} 300-\mathrm{L}_{0} 150-\alpha 70-30 \times 45$ & 300 & $30 \times 45$ & 2418 \\
\hline $\mathrm{R} 1000-\theta 90-\mathrm{L} 300-\mathrm{L}_{0} 150-\alpha 70-30 \times 60$ & 300 & $30 \times 60$ & 2281 \\
\hline $\mathrm{R} 1000-\theta 90-\mathrm{L} 300-\mathrm{L}_{0} 150-\alpha 70-30 \times 75$ & 300 & $30 \times 75$ & 2189 \\
\hline $\mathrm{R} 1000-\theta 90-\mathrm{L} 300-\mathrm{L}_{0} 150-\alpha 70-30 \times 90$ & 300 & $30 \times 90$ & 2112 \\
\hline R1000- $\theta 90-\mathrm{L} 500-\mathrm{L}_{0} 150-\alpha 70$-Perfect & 500 & - & 2371 \\
\hline $\mathrm{R} 1000-\theta 90-\mathrm{L} 500-\mathrm{L}_{0} 150-\alpha 70-30 \times 30$ & 500 & $30 \times 30$ & 2158 \\
\hline $\mathrm{R} 1000-\theta 90-\mathrm{L} 500-\mathrm{L}_{0} 150-\alpha 70-30 \times 45$ & 500 & $30 \times 45$ & 1950 \\
\hline $\mathrm{R} 1000-\theta 90-\mathrm{L} 500-\mathrm{L}_{0} 150-\alpha 70-30 \times 60$ & 500 & $30 \times 60$ & 1814 \\
\hline R1000- $\theta 90-\mathrm{L} 500-\mathrm{L}_{0} 150-\alpha 70-30 \times 75$ & 500 & $30 \times 75$ & 1699 \\
\hline $\mathrm{R} 1000-\theta 90-\mathrm{L} 500-\mathrm{L}_{0} 150-\alpha 70-30 \times 90$ & 500 & $30 \times 90$ & 1607 \\
\hline R1000- $\theta 90-\mathrm{L} 700-\mathrm{L}_{0} 150-\alpha 70$-Perfect & 700 & - & 2104 \\
\hline $\mathrm{R} 1000-\theta 90-\mathrm{L} 700-\mathrm{L}_{0} 150-\alpha 70-30 \times 30$ & 700 & $30 \times 30$ & 1974 \\
\hline $\mathrm{R} 1000-\theta 90-\mathrm{L} 700-\mathrm{L}_{0} 150-\alpha 70-30 \times 45$ & 700 & $30 \times 45$ & 1783 \\
\hline $\mathrm{R} 1000-\theta 90-\mathrm{L} 700-\mathrm{L}_{0} 150-\alpha 70-30 \times 60$ & 700 & $30 \times 60$ & 1630 \\
\hline $\mathrm{R} 1000-\theta 90-\mathrm{L} 700-\mathrm{L}_{0} 150-\alpha 70-30 \times 75$ & 700 & $30 \times 75$ & 1508 \\
\hline R1000- $\theta 90-L 700-\mathrm{L}_{0} 150-\alpha 70-30 \times 90$ & 700 & $30 \times 90$ & 1401 \\
\hline
\end{tabular}

Equation (9) represents the buckling load reduction factor for the cylindrical panel with various lengths $(0.75 \leq$ $L / D \leq 1.75)$, with an elliptical cutout of fixed area $A=$ $8242.5 \mathrm{~mm}^{2}$ and various dimensions $(0.2 \leq a / b \leq 0.5)$ in the midheight position of the shell.

Equation (10) represents the buckling load reduction factor for the cylindrical panel with various lengths $(0.3 \leq$ $L / D \leq 0.5)$, with an elliptical cutout of fixed area $A=$ $8242.5 \mathrm{~mm}^{2}$ and various dimensions $(0.2 \leq a / b \leq 0.5)$ in the midheight position of the shell.

\section{Concluding Remarks}

This study investigated the effect of elliptical cutouts of various sizes in different position on the buckling load of laminated composite cylindrical panel subjected to axial load. The following results were found in this study.

(1) The laminated composite panel with the composite ply angle of $\theta=70$ leads to maximum buckling load for the ply sequence under study, while the ply angle of $\theta=0$ (composite fibers oriented in the longitudinal direction) exhibits the lowest load capacity.

(2) When the width of the cutout is fixed and cutout height increases, the buckling load decreases slightly. Increasing the cutout width while the height of the cutout is fixed reduces the buckling load considerably. Therefore, it is suggested that in designing the panels, the greater cutout dimension is oriented along the longitudinal axis of the panels. 
(3) For the $a / b$ ratio in the range of $0<a / b<1$, when the cutout area is constant an increase in $a / b$ ratio increases the buckling load, and for $a / b>1$ with increase in $a / b$ ratio decrease the buckling load. On the other hand, having $a / b=1$ results in the highest load capacity.

(4) Increasing the panel angle enhances the shell resistance against buckling and increases the amount of the critical load and slender, and longer cylindrical panels are less sensitive to the changes of the panel angle.

(5) Moving the location of the cutout from the midheight of the laminated composite panel to their top end increases the buckling load; slender and longer panels are more sensitive to the change in cutout location.

(6) Finally, formulas were obtained for the computation of the buckling load of cylindrical panels with elliptical cutouts based on the buckling load of perfect cylindrical shells. These expressions are applicable to a wide range of cylindrical panel with elliptical cutouts.

\section{Appendix}

Tables 4 and 5 shows the effect of change in cutout height and cutout width on the buckling load.

\section{References}

[1] R. Hosseinzadeh, M. M. Shokrieh, and L. Lessard, "Damage behavior of fiber reinforced composite plates subjected to drop weight impacts," Composites Science and Technology, vol. 66, no. 1, pp. 61-68, 2006.

[2] M. Zor, F. Şen, and M. E. Toygar, "An investigation of square delamination effects on the buckling behavior of laminated composite plates with a square hole by using threedimensional FEM analysis," Journal of Reinforced Plastics and Composites, vol. 24, no. 11, pp. 1119-1130, 2005.

[3] I. Shufrin, O. Rabinovitch, and M. Eisenberger, "Buckling of laminated plates with general boundary conditions under combined compression, tension, and shear-A semi-analytical solution," Thin-Walled Structures, vol. 46, no. 7-9, pp. 925938, 2008.

[4] H. Akbulut and O. Sayman, "An investigation on buckling of laminated plates with central square hole," Journal of Reinforced Plastics and Composites, vol. 20, no. 13, pp. 11121124, 2001.

[5] F. K. Chang and L. B. Lessard, "Damage tolerance of laminated composites containing an open hole and subjected to compressive loadings-part I: analysis," Journal of Composite Materials, vol. 25, no. 1, pp. 2-43, 1991.

[6] P. Jain and A. Kumar, "Postbuckling response of square laminates with a central circular/elliptical cutout," Composite Structures, vol. 65, no. 2, pp. 179-185, 2004.

[7] M. Yazici, "Influence of cut-out variables on buckling behavior of composite plates," Journal of Reinforced Plastics and Composites, vol. 28, no. 19, pp. 2325-2339, 2008.

[8] S. B. Singh and D. Kumar, "Postbuckling response and failure of symmetric laminated plates with rectangular cutouts under uniaxial compression," Structural Engineering and Mechanics, vol. 29, no. 4, pp. 455-467, 2008.

[9] C. W. Kong, C. S. Hong, and C. G. Kim, "Postbuckling strength of composite plate with a hole," Journal of Reinforced Plastics and Composites, vol. 20, pp. 466-481, 2001.

[10] S. A. M. Ghannadpour, A. Najafi, and B. Mohammadi, "On the buckling behavior of cross-ply laminated composite plates due to circular/elliptical cutouts," Composite Structures, vol. 75, no. 1-4, pp. 3-6, 2006.

[11] Y. H. Kim and A. K. Noor, "Buckling and postbuckling of composite panels with cutouts subjected to combined loads," Finite Elements in Analysis and Design, vol. 22, no. 2, pp. 163185, 1996.

[12] U. K. Mallela and A. Upadhyay, "Buckling of laminated composite stiffened panels subjected to in-plane shear: a parametric study," Thin-Walled Structures, vol. 44, no. 3, pp. 354-361, 2006.

[13] L. S. Kistler and A. M. Waas, "Experiment and analysis on the response of curved laminated composite panels subjected to low velocity impact," International Journal of Impact Engineering, vol. 21, no. 9, pp. 711-736, 1998.

[14] C. Zhang, L. B. Lessard, and J. A. Nemes, "A closedform solution for stresses at curved free edges in composite laminates: a variational approach," Composites Science and Technology, vol. 57, no. 9-10, pp. 1341-1354, 1997.

[15] H. T. Hu and J. S. Yang, "Buckling optimization of laminated cylindrical panels subjected to axial compressive load," Composite Structures, vol. 81, no. 3, pp. 374-385, 2007.

[16] S. Dash, A. V. Asha, and S. K. Sahu, "stability of laminated composite curved panels with cutout using finite element method," in Proceedings of the International Conference on Theoretical, Applied Computational and Experimental Mechanics, Kharagpur, India, 2004.

[17] E. Gal, R. Levy, H. Abramovich, and P. Pavsner, "Buckling analysis of composite panels," Composite Structures, vol. 73, no. 2, pp. 179-185, 2006.

[18] G. M. Stanley, Continuum-based shell elements [Ph.D. dissertation], Department of Mechanical Engineering, Stanford University, 1985.

[19] A. Sabik and I. Kreja, "Stability analysis of multilayered composite shells with cut-outs," Archives of Civil and Mechanical Engineering, vol. 11, no. 1, pp. 195-207, 2011.

[20] H. Ghiasi, D. Pasini, and L. Lessard, "Optimum stacking sequence design of composite materials-part I: constant stiffness design," Composite Structures, vol. 90, no. 1, pp. 1-11, 2009.

[21] H. Ghiasi, K. Fayazbakhsh, D. Pasini, and L. Lessard, "Optimum stacking sequence design of composite materials-part II: variable stiffness design," Composite Structures, vol. 93, no. 1, pp. 1-13, 2010.

[22] M. Shariati, H. R. Allahbakhsh, J. Saemi, and M. Sedighi, "Optimization of foam filled spot-welded column for the crashworthiness design," Mechanika, vol. 83, no. 3, pp. 10-16, 2010.

[23] H. R. Allahbakhsh, J. Saemi, and M. Hourali, "Design optimization of square aluminium damage columns with crashworthiness criteria," Mechanika, vol. 17, no. 2, pp. 187-192, 2011. 

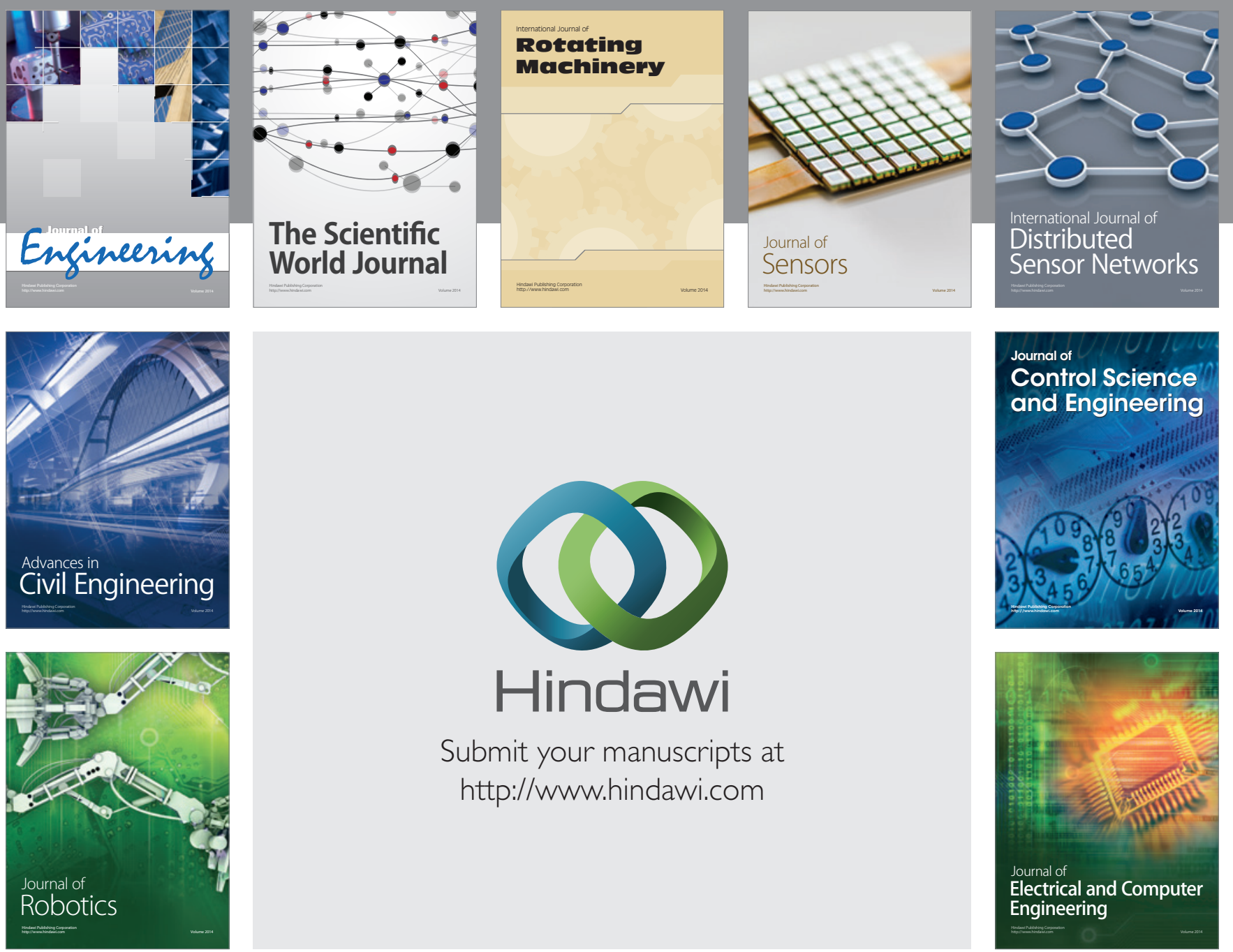

Submit your manuscripts at

http://www.hindawi.com
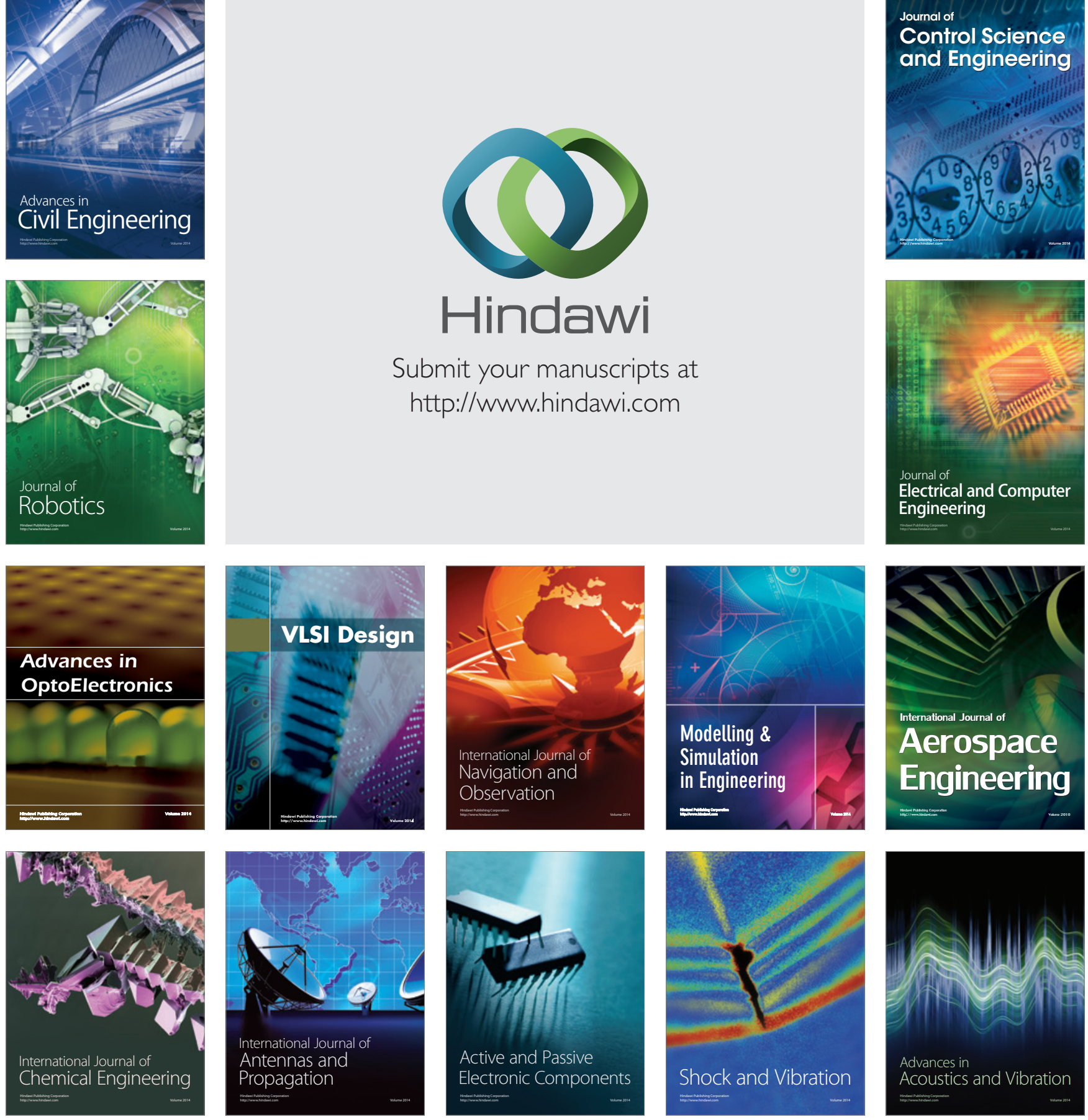